\title{
Metode Fuzzy Subtractive Clustering Dalam Pengelompokkan Penggunaan Energi Listrik Rumah Tangga
}

\author{
Nurul Ramadhanti Hikmiyah ${ }^{1}$; Riki Ruli A. Siregar ${ }^{2}$; Budi Prayitno ${ }^{4}$; \\ Dine Tiara Kusuma ${ }^{5}$ Novi Gusti Pahiyanti ${ }^{6}$ \\ 1, 2, 3, 4, 5 Informatika, Institut Teknologi PLN, Jakarta \\ 6 Teknik Elektro, Institut Teknologi PLN, Jakarta \\ ${ }^{1}$ nuru11631174@itpln.ac.id
}

\begin{abstract}
The use of electricity in household sector has increased, especially during the Covid-19 pandemic. The large number of activities carried out in home such as Work from Home, online schools, and online businesses caused difficulty to monitor the electricity consumption. The absence of electricity usage provisions affects the electricity monitoring process. Hence it takes a real time monitoring application of electricity consumption. Fuzzy subtractive clustering is an unsupervised method to form the number and center of clusters according to data conditions. This method serves to classify the household electricity users with the parameters used, is the amount of usage in rupiah and electric power. The grouping results from this method help users to monitoring electricity consumption in real time. The output describes the level of high, medium and low user electricity consumption. Based on the test results, the best Silhouette Coefficient value is 0.8322535 and three clusters are formed, with an accept ratio is 0.5, a reject ratio of 0.15 , a radius of 1.7 and a squash factor of 0.5 hence a high level of use is obtained with an average value of the number of uses in IDR 655,993, power 2757 VA, medium level 240,553, 1071 VA and low level 46,479, 675 VA.
\end{abstract}

Keywords: Monitoring Electricity Usage, cluster, Fuzzy Subtractive Clustering, Sillhoutte Cofficient, real time

\begin{abstract}
ABSTRAK
Pemakaian listrik pada sektor rumah tangga mengalami peningkatan khususnya pada pandemi covid19. Banyaknya aktivitas yang dilakukan didalam rumah seperti Work from Home, sekolah online, dan bisnis online mengakibatkan sulitnya pemantaun konsumsi listrik. Tidak adanya ketetapan pemakaian listik berpengaruh pada proses pemantauan listrik. Sehingga dibutuhkan aplikasi monitoring pemakaian listrik secara real time. Fuzzy subtractive clustering merupakan metode tidak terawasi untuk membentuk jumlah dan pusat cluster sesuai dengan kondisi data. Metode ini berfungsi untuk mengelompokkan pengguna listrik golongan rumah tangga dengan parameter yang digunakan yaitu jumlah pemakaian dalam rupiah dan daya listrik. Hasil pengelompokkan dari metode tersebut membantu pengguna dalam monitoring pemakaian listrik secara real time. Keluaran yang dihasilkan menggambarkan tingkatan pemakaian listrik pengguna tinggi, sedang dan rendah. Berdasarkan hasil pengujian menunjukkan nilai Silhouette Coefficient terbaik sebesar 0.8322535 dan hasil cluster yang terbentuk sebanyak tiga cluster, dengan nilai accept ratio 0.5 , reject ratio 0.15 , jari-jari 1.7 dan squash factor 0.5 sehingga diperoleh pemakaian tingkat tinggi dengan nilai rata-rata jumlah pemakaian dalam rupiah 655.993, daya 2757 VA, tingkat sedang 240.553, 1071 VA dan tingkat rendah 46.479, 675 VA.
\end{abstract}

Kata kunci: Monitoring pemakaian listrik, cluster, Fuzzy Subtractive Clustering, Sillhoutte Cofficient, real time 


\section{PENDAHULUAN}

Pemakaian listrik pada sektor rumah tangga mengalami peningkatan khususnya semenjak dari tahun 2019 yaitu pada pandemi covid-19. Banyaknya aktivitas yang dilakukan di dalam rumah seperti Work from Home, sekolah online, dan bisnis online mengakibatkan penggunaan energi listrik dan belum mudahnya dalam pemantauan konsumsi listrik. Tidak adanya ketetapan pemakaian listrik berpengaruh pada proses pemantauan listrik [1][2][3]. Persentase penggunaan listrik oleh sektor rumah tangga sebanyak 41,16\% [4]. Detail pemakaian listrik oleh sektor rumah tangga dari tahun 2013 sampai 2018 terkecuali tahun 2016 sebanyak 50.145.446, 53.352.906, 56.649.029, 63.670.247, 66.160.14 [5]. Artinya setiap tahunnya pemakaian listrik pada rumah tangga semakin meningkat [6] [4][7] .

Metode Fuzzy Subtractive Clustering merupakan metode yang mampu memberikan solusi untuk membentuk cluster pengguna listrik berdasarkan pemakaian listrik [8]. Metode ini termasuk algoritma clustering tidak terawasi yang membentuk jumlah dan pusat cluster sesuai dengan kondisi data yang didasarkan atas ukuran densitas titik-titik data dalam variabel. Klasterisasi pengguna listrik golongan rumah tangga dengan parameter yang digunakan yaitu jumlah pemakaian dalam rupiah dan daya listrik. Hasil klasterisasi membentuk urutan tingkatan cluster yang dapat membantu monitoring konsumsi listrik[9][10].

Penelitian terdahulu dengan melakukan desain smart meter untuk memantau dan mengidentifikasikan pemakaian energi listrik pada sektor rumah tangga menggunakan backpropagation neural network [11] yang diterapkan pada penggunaan peralatan elektronik secara real time. Sistem monitoring tersebut di implementasikan dengan cara scanning subnetmask IP (Internet Protocol) perangkat node yang telah terhubung dari alamat IP ke-1 hingga 255. Apabila dari subnetmask IP tersebut memiliki konfigurasi sudah dibuat pada port 81, maka aplikasi tersebut akan mendeteksi alamat IP sebagai alamat dari perangkat node yang terhubung. Building Automation System (BAS) menggunakan smart metering dan koneksi internet [6] merupakan sistem yang dapat mengendalikan pemakaian energi listrik bagi pemilik Gedung [12] [3]. Pengelompokkan data potensi kebakaran hutan atau lahan dengan metode fuzzy subtractive clustering [13] yaitu sistem yang mampu mengelola data titik api (hotspot) dengan parameter suhu kecerahan dan FRP (Fire Radiative Power). Output berupa hasil pengklasteran yang menggambarkan potensi kebakaran hutan, dikelompokkan dalam potensi rendah dan tinggi. Selanjutnya di penelitian mengenai pendekatan pada implementasi model subtractive clustering dalam klasifikasi data perilaku konsumen listrik tegangan rendah [14]. Memiliki tujuan untuk memberikan Analisa pola beban pemakaian listrik dan implementasi Advanced Metering Infrastructure (AMI) atau sebagai smart meter PLN (Persero) dengan melakukan pengelompokkan terhadap pemakaian listrik 1 phasa dan 3 phasa di pelanggan PT PLN (Persero) UP3 Cengkareng selama 4 bulan.

Pada penelitian ini, aplikasi yang digunakan dalam monitoring pemakaian listrik dinamakan smart kWh meter. Metode yang digunakan pada penelitian ini yaitu Fuzzy Subtractive Clustering. Keluaran yang dihasilkan menggambarkan tingkatan pemakaian listrik pengguna tinggi, sedang dan rendah. Bertujuan untuk membantu pengguna dalam monitoring pemakaian listrik secara real time sebagai keputusan dalam optimalisasi penggunaan energi listrik pada rumah tangga [10][9] [15].

\section{METODE/PERANCANGAN PENELITIAN}

Fuzzy subtractive clustering merupakan algoritma clustering tidak terawasi yang membentuk jumlah dan pusat cluster sesuai dengan kondisi data. Dalam analisis kluster ada dua metode pengelompokkan, yaitu metode berhirarki (hierarchical methods) dan metode tidak berhirarki (nonhierarchical methods). Pada proses pengelompokkan (clustering) berhirarki atau tidak 
berhirarki, pembentukan kelompok dilakukan sedemikian rupa sehingga setiap objek berada tepat pada satu kelompok. Akan tetapi, pada suatu saat hal itu tidak dapat dilakukan, karena sebenarnya objek tersebut terletak di antara dua atau lebih kelompok yang lain. Sehingga perlu dilakukan pengelompokkan dengan menggunakan fuzzy clustering dimana dalam melakukan pengelompokkan mempertimbangkan tingkat keanggotaan himpunan fuzzy sebagai dasar pembobotan [4]. Subtractive clustering didasarkan atas ukuran densitas titik-titik data dalam variabel. Konsep dasarnya menentukan daerah-daerah dalam suatu variabel yang memiliki densitas tinggi terhadap titik-titik disekitarnya. Titik dengan jumlah tetangga terbanyak akan dipilih sebagai pusat cluster. Titik yang terpilih menjadi pusat cluster selanjutnya dikurangi densitas. Kemudian algoritma memilih titik lain yang mempunyai tetangga terbanyak untuk dijadikan pusat cluster yang lain. Dilakukan secara berulang sehingga semua titik diuji.

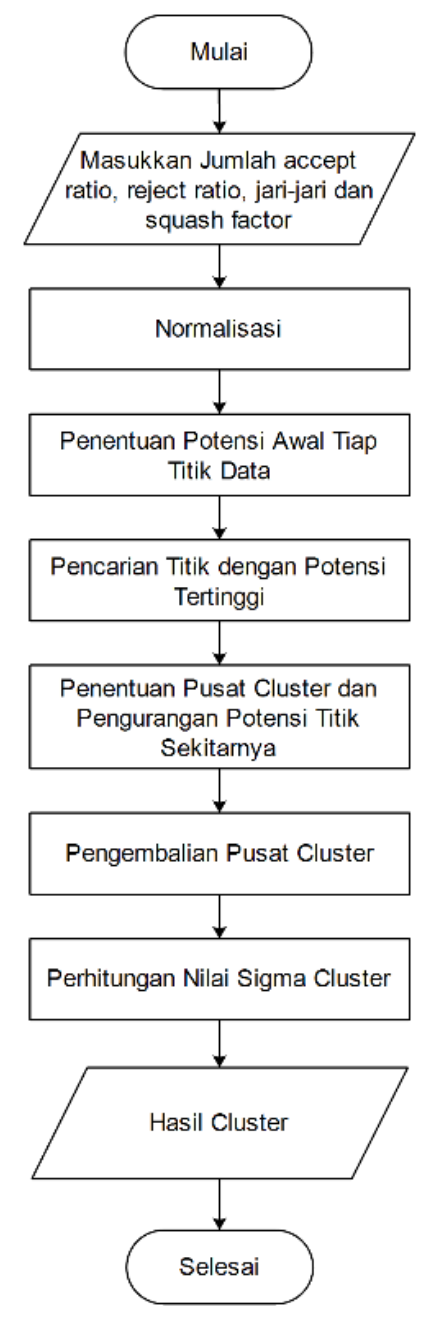

Gambar 1. Diagram Alur Perhitungan Metode

Jika ada $\mathrm{n}$ buah data: X1, X2,.., Xn dan data-data tersebut dianggap dalam keadaan normal, maka densitas titik Xk dapat dihitung sebagai berikut :

$$
D k=\sum_{k=0}^{n} \exp \left(-\frac{\|X k-X j\|}{\left(\frac{r}{2}\right)^{2}}\right)
$$


Dengan $\|\mathrm{Xk}-\mathrm{Xkj}\|$ merupakan jarak antara Xk dengan $\mathrm{Xj}$ dan $\mathrm{r}$ adalah konstanta positif yang dinamakan jari-jari. Jari- jari dapat menentukan sedikit banyaknya pengaruh pusat cluster tiap variabel. Maka dari itu, suatu titik data akan memiliki densitas besar jika tetangga dekat banyak. Selanjutnya titik yang densitas tertinggi dipilih menjadi pusat cluster. Contohnya Xc1 titik terpilih sebagai pusat cluster, Dc1 menjadi ukuran densitas. Kemudian densitas titik disekitarnya dikurangi menjadi sebagai berikut [11]:

$$
D k=D k-D c 1 * \exp \left(-\frac{\|X k-X j\|}{r_{(}^{r b}-{ }^{2}}\right) \quad(2.2)
$$

Dengan rb adalah konstanta positif, maka titik yang dekat dengan pusat cluster uc1 dikurangi densitas terbesar sehingga sulit untuk menjadi pusat cluster baru. rb bernilai lebih besar daripada $\mathrm{r}$, $\mathrm{rb}=\mathrm{q}$ *. Selanjutnya dicari pusat cluster yang kedua. Ukuran densitas setiap titik data akan diperbaiki kembali, dan dikerjakan berulang. Dapat digunakan dua pecahan menjadi faktor pembanding, berupa accept ratio dan reject ratio. Accept ratio adalah batas bawah, titik data dijadikan calon pusat cluster dapat menjadi pusat cluster. Sedangkan reject ratio yaitu batas atas, titik data calon pusat cluster tidak dapat dijadikan pusat cluster. Terdapat tiga kondisi pada suatu iterasi [11]:

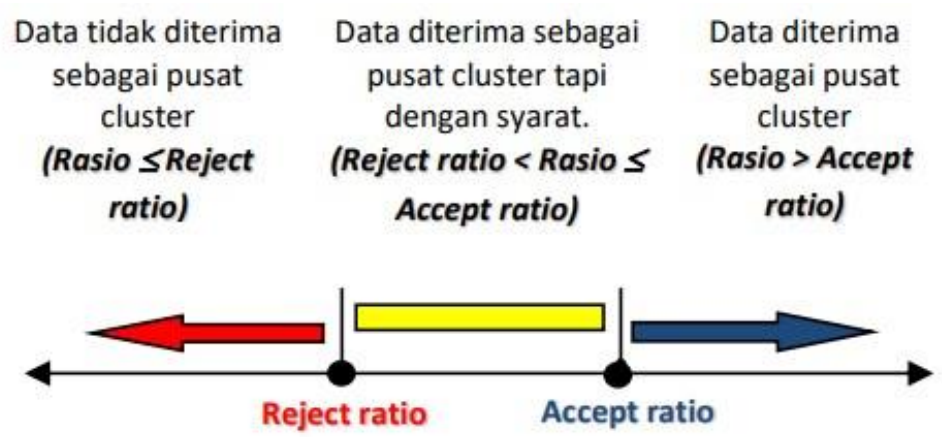

Gambar 2. Kondisi dalam Proses Iterasi

\section{HASIL DAN PEMBAHASAN}

Berdasarkan perancangan aplikasi smart kwh meter untuk monitoring pemakaian listrik secara real time digunakan oleh pengguna listrik [3]. Pada aplikasi ini pengguna dapat mengetahui detail pemakaian dalam harian, mingguan, bulanan dan tahunan. Serta pengguna mengetahui kategori pemakaian listrik termasuk kedalam pemakaian rendah, sedang atau tinggi. Hal ini dapat membantu pengguna dapat mengontrol konsumsi listrik. 

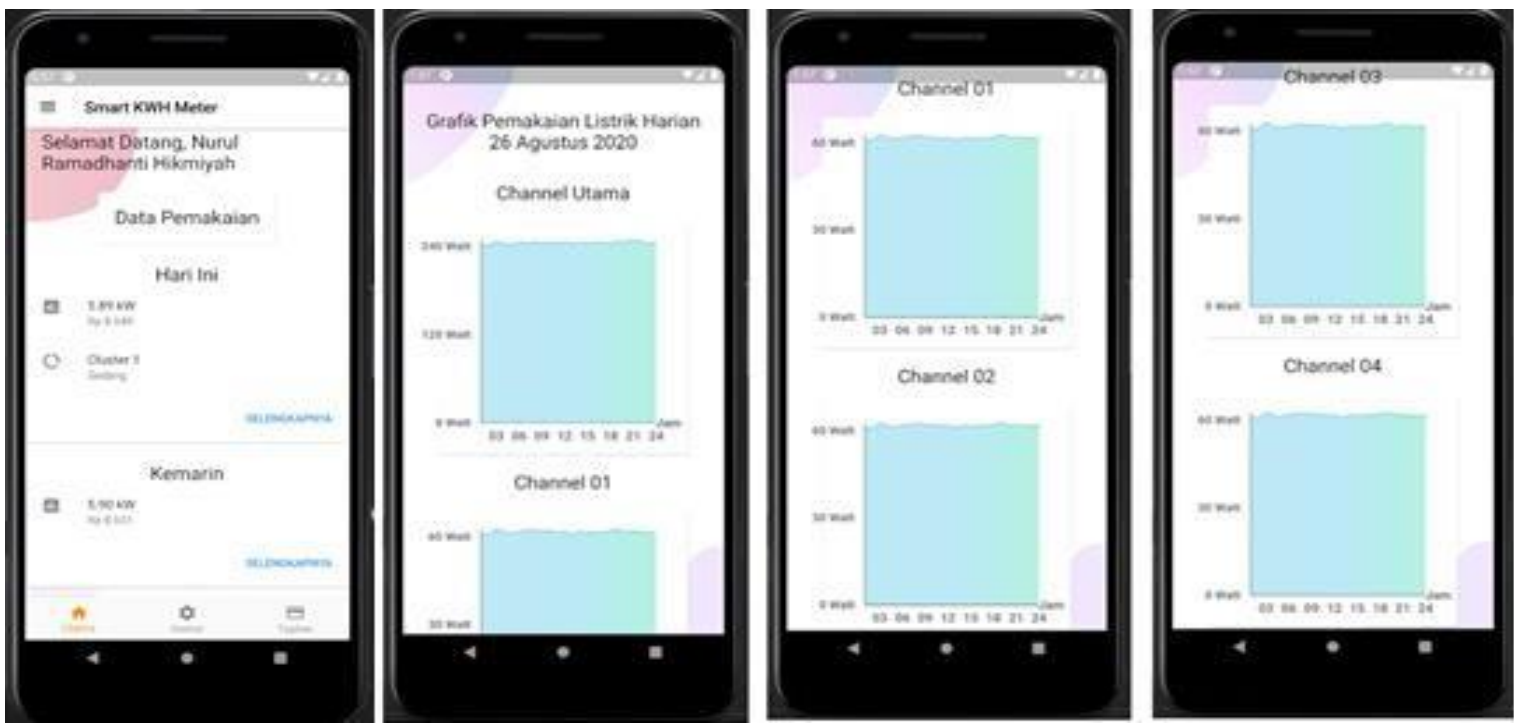

Gambar 3. Tampilan Monitoring Pemakaian Listrik Secara Real Time

Penelitian dilakukan berdasarkan hasil observasi dari pelanggan listrik PLN golongan rumah tangga R1-R2 dengan daya 450 sampai 3500 VA. Dari hasil observasi yang telah dilakukan, ditemukan suatu masalah yaitu pada penggunaan listrik yang mengalami peningkatan secara signifikan khususnya pada sektor rumah tangga. Pengguna listrik tidak mengetahui masuk ke dalam kelompok mana dalam klasterisasi dengan jumlah pemakaian listrik yang sama. Untuk mengetahui jumlah pemakaian listrik secara real time dibuatkannya sebuah aplikasi yang membantu pengguna dengan menerapkan metode Fuzzy Subtractive Clustering. Dengan metode tersebut menghasilkan anggota kelompok dari masing-masing klaster berdasarkan pemakaian listrik yang memiliki daya dan jumlah pemakaian listrik berbeda.

Tabel 1. Hasil Rata-Rata Setiap Atribut

\begin{tabular}{|l|l|l|l|l|l|}
\hline \multicolumn{5}{|l|}{ Rata-rata Setiap Atribut pada Cluster ke- } \\
\hline 1 & 2 & 3 & \multicolumn{2}{l|}{} \\
\hline $\begin{array}{l}\text { Jumlah } \\
\text { Pemakaian } \\
\text { dalam Satu } \\
\text { Bulan }\end{array}$ & Daya & $\begin{array}{l}\text { Jumlah Pemakaian dalam } \\
\text { Satu }\end{array}$ & Daya & $\begin{array}{l}\text { Jumlah } \\
\text { Pemakain } \\
\text { dalam } \\
\text { Satu Bulan }\end{array}$ & Daya \\
\hline 240552.7157 & 1071.428571 & 655992.6772 & 2757.142857 & 46478.50101 & 675 \\
\hline
\end{tabular}

Pada tabel 1, menunjukkan bahwa pada peringkat urutan pertama yaitu cluster dua memiliki rata-rata jumlah pemakaian dalam satu bulan yang tinggi dan diiringi dengan kapasitas daya yang tinggi. Pada urutan kedua pada cluster satu memiliki rata-rata jumlah pemakaian dalam satu bulan dan kapasitas daya yang sedang. Sedangkan pada urutan ketiga pada cluster tiga memiliki rata-rata jumlah pemakaian dalam satu bulan dan kapasitas daya cenderung rendah. Hal ini menunjukkan 
bahwa jumlah pemakaian dalam satu bulan dan kapasitas daya memiliki keterkaitan satu sama lain dalam pemakaian listrik oleh pengguna.

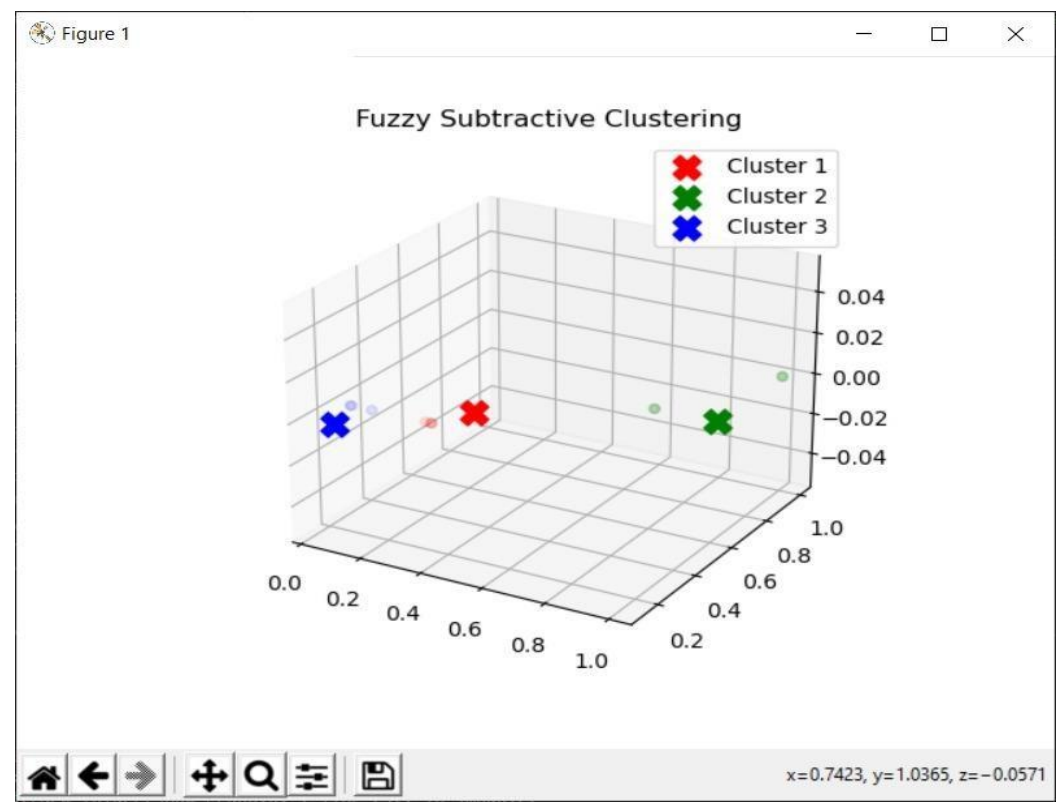

Gambar 4. Hasil Klasterisasi dengan Metode Fuzzy Subtractive Clustering

Pada gambar 4 pada pemakaian listrik bulanan menjelaskan bahwa cluster 1 dengan pusat cluster [0.373026588, 0.371428571] berisi pengguna atau pelanggan listrik ke- 1, 2, 9, 10, 11 . Sedangkan pada cluster 2 dengan pusat cluster [0.998647079, 0.628571429] berisi pengguna atau pelanggan listrik ke-4, 5, 6, 8, 12,13, 14 dan cluster 3 dengan pusat cluster [0.082090829, 0.128571429 ] berisi pengguna atau pelanggan listrik ke- 3, 7, 16, 17, 18, 20. Pada masing-masing pelanggan membentuk titik-titik dalam perhitungan metode tersebut dan titik-titik yang berdekatan akan membentuk satu kelompok. Pelanggan dapat mengetahui anggota kelompok yang sama dari 20 pelanggan tersebut

Pada penelitian ini, proses pengujian terhadap data pemakaian listrik pada golongan rumah tanggan R1-R2 dengan daya 450-350 menggunakan data dummy sebanyak 20 pengguna pemakaian listrik. Berdasarkan hasil pengujian yang telah dilakukan, didapatkan nilai hasil pengujian menggunakan Silhouette Cofficient perbandingan antar satu cluster dengan cluster lainnya yaitu reject ratio, jari-jari dan squash factor mempengaruhi hasil rata-rata Silhouette. Pengujian tersebut dilakukan dengan mengambil jari-jari 0.1 sampai 3.3, dimana dihasilkan nilai rata-rata Silhouette yang naik turun, dan puncak dari klaster terbaik ketika jari-jari berada pada range 1.6 sampai 1.7. Kondisi pada jari-jari 3.4 tidak dapat menghasilkan rata-rata Silhouette karena hanya menghasilkan 1 cluster. Hal ini tidak dapat mengakibatkan perhitungan pengujian dihentikan pada pengujian jarijari dikarenakan tidak ada perbandingan antar cluster. Dengan menggunakan accept ratio, reject ratio, jari-jari dan squash factor $0.5,0.15,1.7,0.5$ maka klaster tersebut dikatakan kuat dan bagus karena nilai rata-rata silhouette coefficient mendekati 1.

Hasil Pengujian Pengaruh Accept ratio. Pengujian dimulai dengan memasukkan nilai accept ratio yang berbeda setiap pengujiannya, accept ratio adalah batas bawah diperbolehkannya suatu data menjadi pusat cluster. Nilai accept ratio yang digunakan 0.1 sampai 1.0. Pengujian jumlah terhadap pengaruh nilai accept ratio dilakukan dengan menggunakan data dummy pemakaian listrik golongan rumah tangga sebanyak 20 pengguna. 


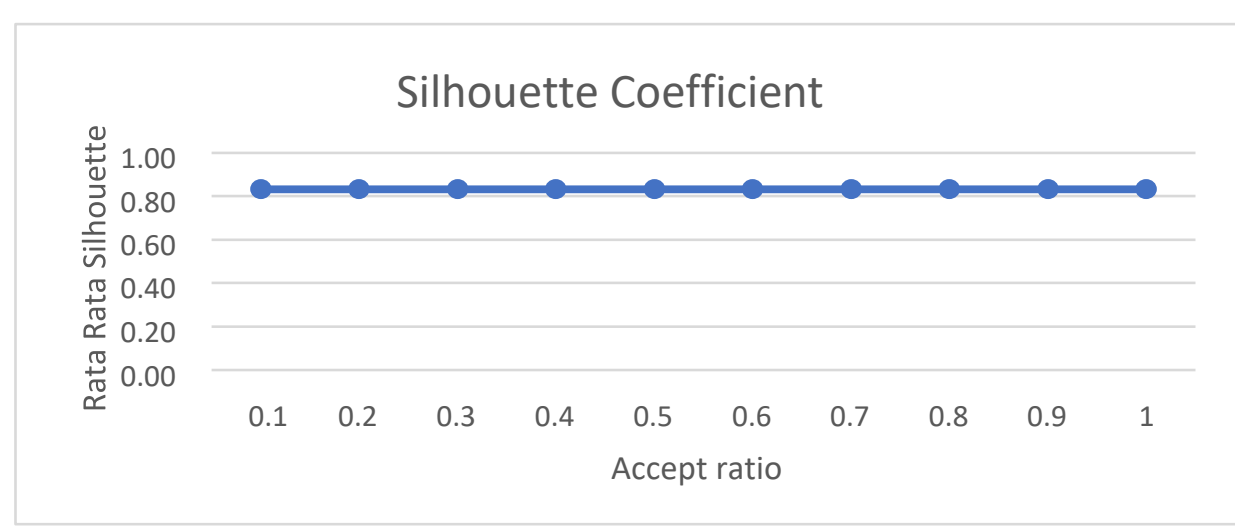

Gambar 5. Grafik Pengujian Accept ratio

Pengujian pertama menunjukkan bahwa parameter accept ratio tidak berpengaruh terhadap pembentukan cluster, hal ini dapat dilihat dari hasil pengujian yang menggunakan parameter accept ratio dengan nilai 0.1 sampai 1.0 pada accept ratio yang sama menghasilkan jumlah cluster dan nilai rata-rata silhouette yang sama sebanyak 0.8 . Accept ratio tidak berpengaruh karena nilai accept ratio yang dipergunakan sebagai batas bawah di mana suatu titik data yang menjadi kandidat pusat cluster tidak diperbolehkan menjadi pusat cluster lebih besar dari nilai reject ratio.

a. Pengujian Pengaruh Reject ratio

Pengujian ini dilakukan untuk mengetahui pengaruh antara nilai Reject ratio dengan nilai rata-rata silhouette. Reject ratio merupakan nilai batas atas di mana suatu titik data yang menjadi kandidat calon pusat cluster tidak diperbolehkan menjadi pusat cluster.Data yang digunakan sebanyak 20 data. Berdasarkan pengujian pertama telah diketahui bahwa nilai accept ratio tidak berpengaruh pada hasil pengujian, pada pengujian ini nilai accept ratio yang digunakan adalah 0.5 dan nilai reject ratio 0.15 sampai 0.50 .

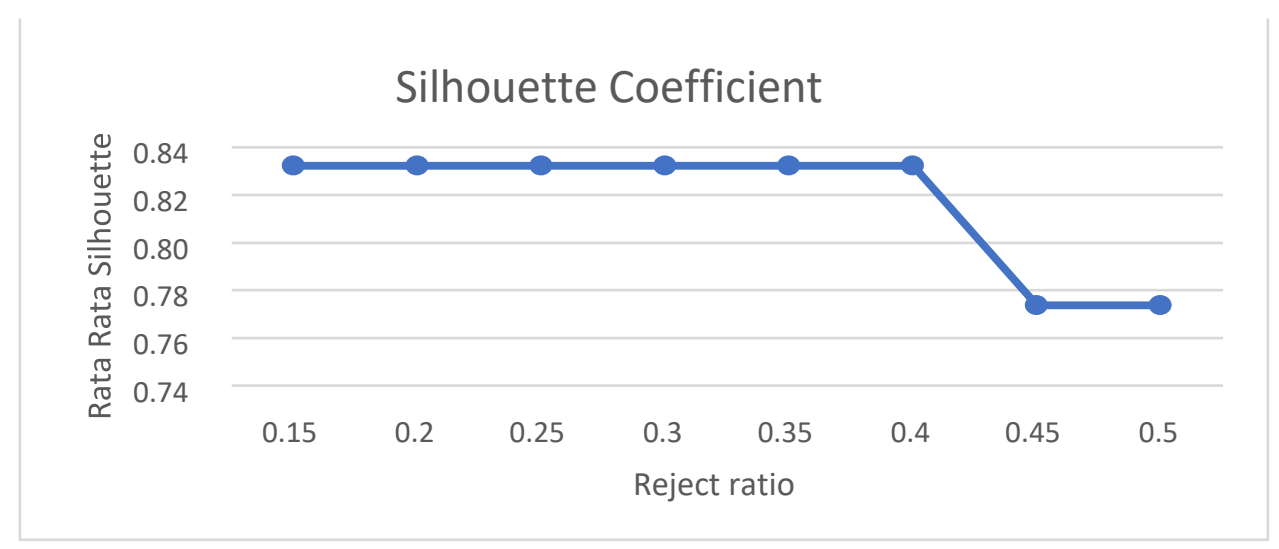

Gambar 6. Grafik Pengujian Accept ratio

Pada pengujian ini menunjukkan di gambar 6, bahwa nilai nilai rata-rata silhouette pada reject ratio optimal terbaik dari range $0.15-0.4$, apabila nilai reject ratioilebih dari 0.4 maka maka nilai ratarata silhouette akan semakin kecil.

b. Pengujian Pengaruh Jari-jari

Pada pengujian pengaruh nilai jari-jari digunakan nilai jari jari 0.1 sampai 3.3 dengan nilai reject ratio diambil dari nilai terbaik pada pengujian sebelumnya 0.15 dan nilai accept ratio 0.5. Nilai hasil silhouette coefficient terletak pada kisaran nilai -1 hingga 1. Semakin nilai 
silhouette coefficient mendekati nilai 1, maka semakin baik pengelompokan data dalam satu cluster. Sebaliknya jika silhouette coefficient mendekati nilai -1, maka semakin buruk pengelompokan data didalam satu cluster.

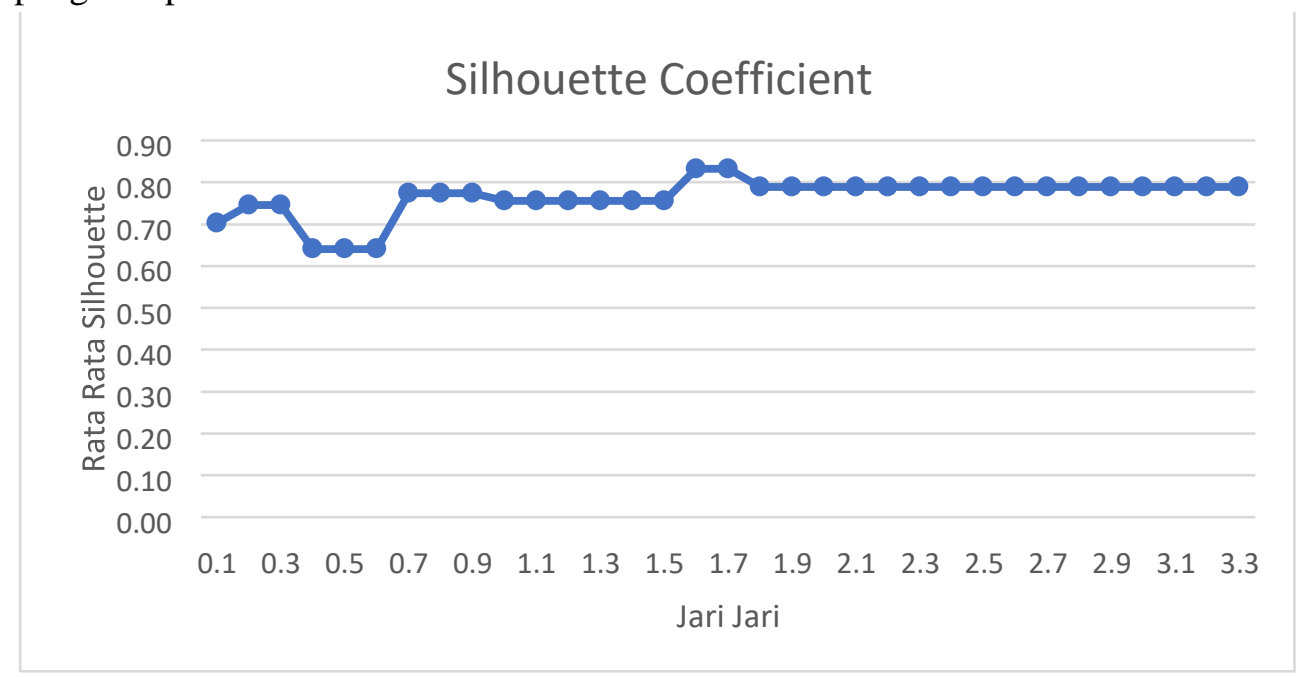

Gambar 7. Grafik Pengujian SilhouetteCofficient

Pada gambar 7, menjelaskan bahwa hasil pengujian menggunakan Silhouette Cofficient perbandingan antar satu cluster dengan cluster lainnya yaitu nilai jari-jari mempengaruhi hasil ratarata Silhouette. Pengujian dilakukan dengan mengambil jari-jari 0.1 sampai 3.3, dimana dihasilkan nilai ratarata Silhouetteyang naik turun, dan puncak dari klaster terbaik ketika jari-jari berada pada range 1.6 sampai 1.7. Kondisi pada jari-jari 3.4 tidak dapat menghasilkan rata-rata Silhouette karena hanya menghasilkan 1 cluster. Hal ini tidak dapat mengakibatkan perhitungan pengujian dihentikan pada jarija dikarenakan tidak ada perbandingan antar cluster. Dengan menggunakan jari-jari 1.6 - 1.7 maka klaster tersebut dikatakan kuat dan bagus.

c. Pengujian Pengaruh Squah Factor

Pada pengujian pengaruh nilai squash factor digunakan nilai jari jari 0.1 sampai 3.3. Dengan menggunakan accept ratio 0.5 , reject ratio 0.15 dan jari-jari 1.7 sebagai berikut:

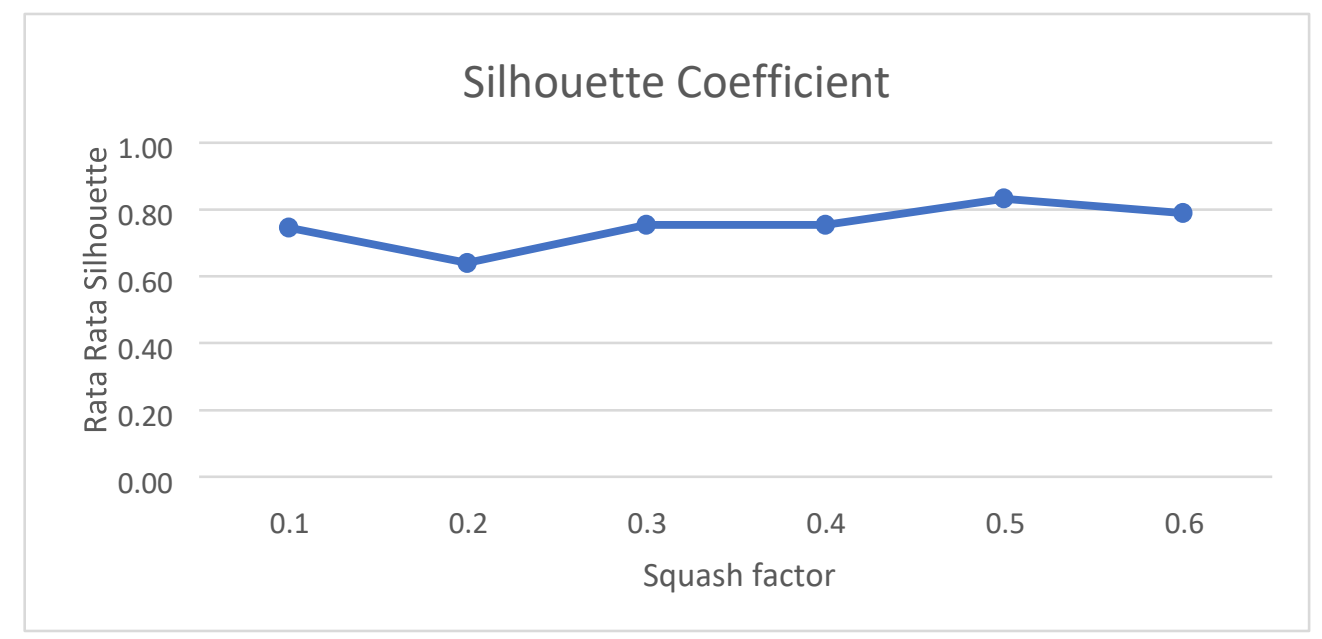

Gambar 8. Grafik Pengujian Squash Factor 
Pada pengujian pengaruh nilai di gambar 8, silhouette terhadap nilai squash factor menunjukkan pada pengujian menunjukkan bahwa pemberian nilai squash factor yang berbeda menghasilkan nilai rata-rata silhouette yang berbeda pula. Pengujian tersebut nilai rata-rata silhouette naik turun dan nilai terbaik ada pada nilai 0.5 .

\section{KESIMPULAN DAN SARAN}

\subsection{KESIMPULAN}

Berdasarkan hasil penelitian dan pembahasan yang telah dilakukan dapat diambil kesimpulan bahwa Aplikasi yang digunakan untuk monitoring pemakaian listrik secara real time berupa aplikasi smart $\mathrm{kWh}$ meter berbasis android. Aplikasi dapat digunakan oleh pengguna listrik untuk memantau dan mengontrol pemakaian listrik secara real time. Aplikasi tersebut hasil implementasi dari metode Fuzzy Subtractive Clustering pada klasterisasi pengguna berdasarkan pemakaian listrik menggunakan data dummy pengguna golongan rumah tangga R1-R2 dengan range daya 450-3500 VA yang telah dihitung sehingga menghasilkan 3 cluster. Cluster pertama terdiri dari pengguna listrik ke- 1, 2, 9, 10,11, 15, 19, cluster kedua terdiri dari pengguna listrik ke- 4, 5, 6, 8, 12, 13, 14, dan cluster ketiga terdiri dari pengguna listrik 3, 7, 16, 17, 18, 20. Berdasarkan hasil cluster tersebut menghasilkan urutan cluster, peringkat urutan pertama yaitu cluster dua memiliki rata-rata jumlah pemakaian dalam satu bulan yang tinggi dan diiringi dengan kapasitas daya yang tinggi. Pada urutan kedua pada cluster satu memiliki rata-rata jumlah pemakaian dalam satu bulan dan kapasitas daya yang sedang. Sedangkan pada urutan ketiga pada cluster tiga memiliki rata-rata jumlah pemakaian dalam satu bulan dan kapasitas daya cenderung rendah. Urutan cluster tersebut menunjukkan bahwa jumlah pemakaian dalam satu bulan dan kapasitas daya memiliki keterkaitan satu sama lain dalam pemakaian listrik oleh pengguna. Hal ini dapat membantu pengguna dalam monitoring pemakaian listrik karena diketahui perbandingan tinggi rendahnya antar cluster. Berdasarkan hasil pengujian menunjukkan nilai Silhouette Coefficient terbaik sebesar 0.8322535 dan hasil cluster yang terbentuk sebanyak tiga cluster, dengan nilai accept ratio 0.5 , reject ratio 0.15 , jarijari 1.7 dan squash factor 0.5 sehingga diperoleh pemakaian tingkat tinggi dengan nilai rata-rata jumlah pemakaian dalam rupiah 655.993, daya $2757 \mathrm{VA}$, tingkat sedang 240.553, $1071 \mathrm{VA}$ dan tingkat rendah 46.479, 675 VA.

\subsection{SARAN}

Dari hasil penelitian yang telah dilakukan, terdapat beberapa hal yang ingin disarankan untuk pengembangan aplikasi ini untuk penelitian selanjutnya, yaitu:

1. Klasterisasi pemakaian listrik dapat dikembangkan dengan menggunakan metode klasifikasi sehingga dapat menghasilkan klasifikasi kategori pemakaian listrik.

2. Untuk pengembangan dari penelitian ini dapat menggunakan data yang lebih aktual. Agar dampak negatif yang ditimbulkan dapat berkurang di kalangan masyarakat.

3. Untuk penelitian dan penulisan skripsi ini dapat menjadi bahan acuan bagi pembaca dan penulis sendiri untuk pengembangan aplikasi sejenis. Sehingga menambah wawasan dan menghasilkan sumber daya manusia yang aktif dan berkompeten dikemudian hari. 


\section{DAFTAR PUSTAKA}

[1] J. Lloret, J. Tomas, A. Canovas, and L. Parra, "An Integrated IoT Architecture for Smart Metering," IEEE Commun. Mag., vol. 54, no. 12, pp. 50-57, Dec. 2016, doi: 10.1109/MCOM.2016.1600647CM.

[2] "KWh Meter Smart Card Model Token For Electrical Energy Monitoring," MATEC Web Conf., vol. 218, p. 03002, 2018, doi: 10.1051/matecconf/201821803002.

[3] R. R. A. Siregar, Y. K. Ningsih, P. Palupiningsih, and B. Prayitno, "Smart kWh Meter Model with Energy Control and Monitoring on Low Voltage Electricity," pp. 227-232, Dec. 2020, doi: 10.2991/AER.K.201221.039.

[4] R. F. Ningrum, R. R. A. Siregar, and D. Rusjdi, "Fuzzy mamdani logic inference model in the loading of distribution substation transformer SCADA system," IAES Int. J. Artif. Intell., vol. 10, no. 2, pp. 298-305, Jun. 2021, doi: 10.11591/IJAI.V10.I2.PP298-305.

[5] Samudin Harsanto, "Statistik Listrik 'Electric Statistic' 2013-2018," BPS-Statistic Indonesia, 2018.

[6] O. : Akhyar and Zaini, "Building Automation System (BAS) Menggunakan Smart Metering Dan Koneksi Internet,” J. Teknoif, vol. 6, no. 2, 2018, doi: 10.21063/JTIF.2018.V6.2.

[7] P. Catur Siswipraptini, R. Nur Aziza, M. Asura, R. R. A. Siregar, and M. Abdul Jabar, "KMeans Clustering Algorithm for Smart Home Automation," 2020 8th Int. Conf. Control. Mechatronics Autom. ICCMA 2020, pp. 207-211, Nov. 2020, doi: 10.1109/ICCMA51325.2020.9301506.

[8] R. Pereira, A. Fagundes, R. Melício, V. M. F. Mendes, J. Figueiredo, and J. C. Quadrado, "Fuzzy Subtractive Clustering Technique Applied to Demand Response in a Smart Grid Scope," Procedia Technol., vol. 17, pp. 478-486, 2014, doi: 10.1016/j.protcy.2014.10.256.

[9] M. Abbas and D. Zhang, "A smart fault detection approach for PV modules using Adaptive Neuro-Fuzzy Inference framework," Energy Reports, vol. 7, pp. 2962-2975, 2021, doi: 10.1016/j.egyr.2021.04.059.

[10] U. Mohan Rao, Y. R. Sood, and R. K. Jarial, "Subtractive clustering fuzzy expert system for engineering applications," Procedia Comput. Sci., vol. 48, no. C, pp. 77-83, 2015, doi: 10.1016/j.procs.2015.04.153.

[11] G. U. Kaya, O. Erkaymaz, and Z. Sarac, "Optimization of digital holographic setup by a fuzzy logic prediction system,” Expert Syst. Appl., vol. 56, 2016, doi: 10.1016/j.eswa.2016.03.019.

[12] R. F. Ningrum, R. R. A. Siregar, and D. Rusjdi, "Penerapan Sistem SCADA Dalam Perancangan Model Inferensi Logika Fuzzy Mamdani Pada Pembebanan Trafo Gardu Distribusi," Petir J. Pengkaj. dan Penerapan Tek. Inform., vol. 13, no. 2, pp. 110-118, Sep. 2020, doi: 10.33322/PETIR.V13I2.1001.

[13] "Implementasi Metode Fuzzy Subtractive Clustering Untuk Pengelompokan Data Potensi Kebakaran Hutan/Lahan | Jurnal Pengembangan Teknologi Informasi dan Ilmu Komputer." [Online]. Available: https://j-ptiik.ub.ac.id/index.php/j-ptiik/article/view/271. [Accessed: 11Sep-2021].

[14] Y. Arvio, I. B. Sangadji, H. Sikumbang, and M. D. Anjarwati, "Pendekatan Implementasi Model Substractive Clustering Dalam Memetakan Dan Klasifikasi Data Perilaku Konsumen Listrik Tegangan Rendah Studi Kasus : Pelanggan PT PLN (Persero) UP3 Cengkareng," Petir J. Pengkaj. dan Penerapan Tek. Inform., vol. 12, no. 2, pp. 251-261, Sep. 2019, doi: 10.33322/PETIR.V12I2.553.

[15] P. C. Siswipraptini, R. Nur Aziza, I. B. M. Sangadji, I. Indrianto, and R. R. A. Siregar, "Automated Smart Home Controller Based on Adaptive Linear Neural Network," 2019 IEEE 
PETIR: Jurnal Pengkajian dan Penerapan Teknik Informatika Vol. 14, No. 2, September 2021, P-ISSN 1978-9262, E-ISSN 2655-5018 DOI: https://doi.org/10.33322/petir.v14i2.1448

7th Int. Conf. Control. Mechatronics Autom. ICCMA 2019, pp. 423-427, 2019, doi: 10.1109/ICCMA46720.2019.8988733. 